\title{
Endovascular Stenting for the Treatment of an Initially Asymptomatic Patient with Traumatic Carotid Artery Dissection
}

\author{
So Hui Yun and Jong Cook Park \\ Department of Anesthesiology and Pain Medicine, Jeju National University Hospital, Jeju National University School of Medicine, Jeju, Korea
}

\section{Dear Editor:}

Carotid dissection is a rare lesion after head injury and is often known to occur in the case of direct neck trauma. Although most of the carotid artery dissection occurs spontaneously, approximately $4 \%$ is associated with severe trauma [1]. For example, major blunt trauma resulting from high-speed motor vehicle accidents [2]. Clinical presentation encompasses a wide range of symptoms, often leading to a delay in diagnosis. Asymptomatic carotid artery injury may not be easily detected during clinical evaluation of head and neck trauma $[3,4]$.

\section{Case}

A 78-year-old woman was admitted after being hanging while experiencing a cart wearing a scarf 1 day ago. She had a history of hypercholesterolemia. The neck computed tomography (CT) scan showed bilateral common carotid artery dissection (Figure 1A and B), with patent blood flow and hematoma with swelling in the pretracheal area (Figure 1C). However, the true and false lumen could not be clearly distinguished and the true lumen was not compressed (Figure 1D). There was no problem with perfusion through the bilateral internal carotid artery. The patient was hemodynamically stable and without neurological deficits. We planned followup $\mathrm{CT}$ after 3 days and the patient will be transfer to her home region if there is no change in the lesion.

Three days later, the patient complained of sudden severe dizziness. Patients were drowsy on the day of imaging follow-up with nausea and poor oral intake, and the Glasgow Coma Scale decreased from 4-5-6 to 3-4-6. Therefore, emergency transfemoral cerebral angiography and diffusion magnetic resonance imaging were performed. The magnetic resonance imaging showed multiple tiny high signal in-
Received on January 4, 2017

Revised on April 10, 2017

Accepted on May 4, 2017

Jong Cook Park

Department of Anesthesiology and Pain Medicine, Jeju National University Hospital, 15 Aran 13-gil, Jeju 63241, Korea

Tel: $+82-64-717-2028$

Fax: +82-64-717-2042

E-mail: pjcook@jejunu.ac.kr

*No potential conflict of interest relevant to this article was reported. 

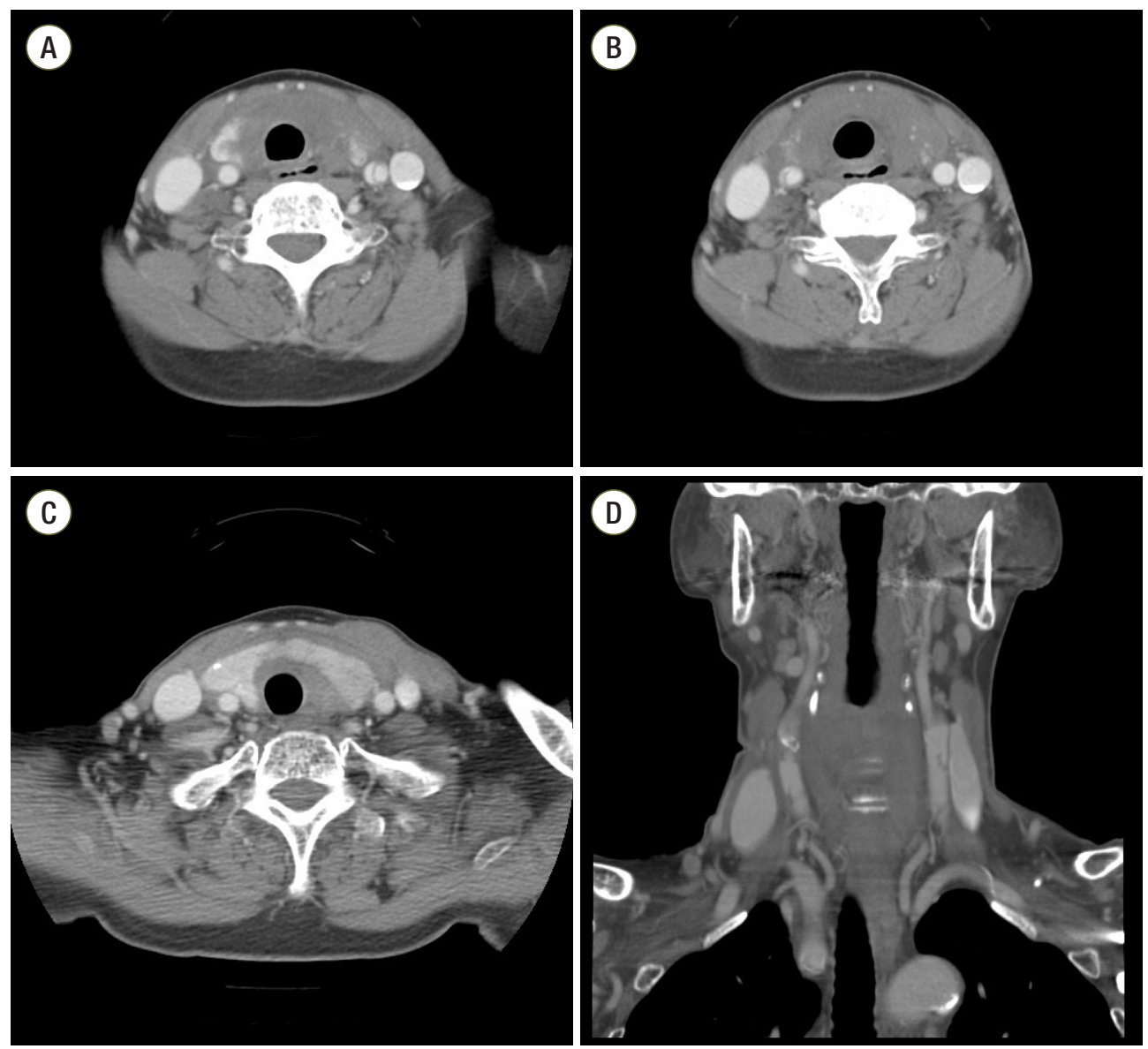

Figure 1. Neck computed tomography scan showing dissections of both common carotid arteries, mid portion. (A) The 2.6-cm segmental intimal flap in the left common carotid artery. (B) A short segmental intimal flap in the right common carotid artery. (C) Diffuse hematoma around the thyroid gland in the anterior neck. (D) Coronal view showing both common carotid artery dissections.

tensities with acute lacunar infarct in both cerebral white matter (Figure 2). On the transfemoral cerebral angiography, the dissection was observed in distal parts of both common carotid arteries and flow flap. As a result, spontaneous healing could not be expected, and endovascular stent insertion was performed in both common carotid arteries (Figure 3). We inserted $10 \mathrm{~mm} \times 60 \mathrm{~mm}$ sized self-expanding Nitinol stents on each side without embolic protection device or ballooning.

After stent insertion, we started antithrombotic therapy (clopidogrel $75 \mathrm{mg}$ and aspirin $100 \mathrm{mg}$ per day as oral medications). The patient was discharged about 2 weeks later, complaining only of pain in the anterior neck without any specific neurologic deficiency. The study was performed according to the Helsinki Declaration and ap-

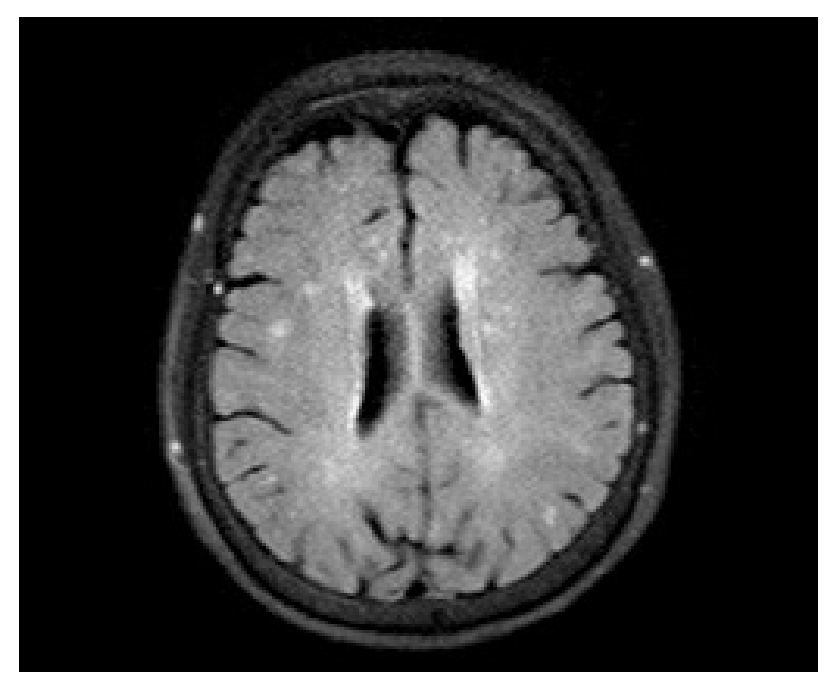

Figure 2. Brain diffusion magnetic resonance image showing a tiny diffusion-restricted lesion in the left frontal white matter. Multiple tiny high signal intensities in both cerebral white matter. 

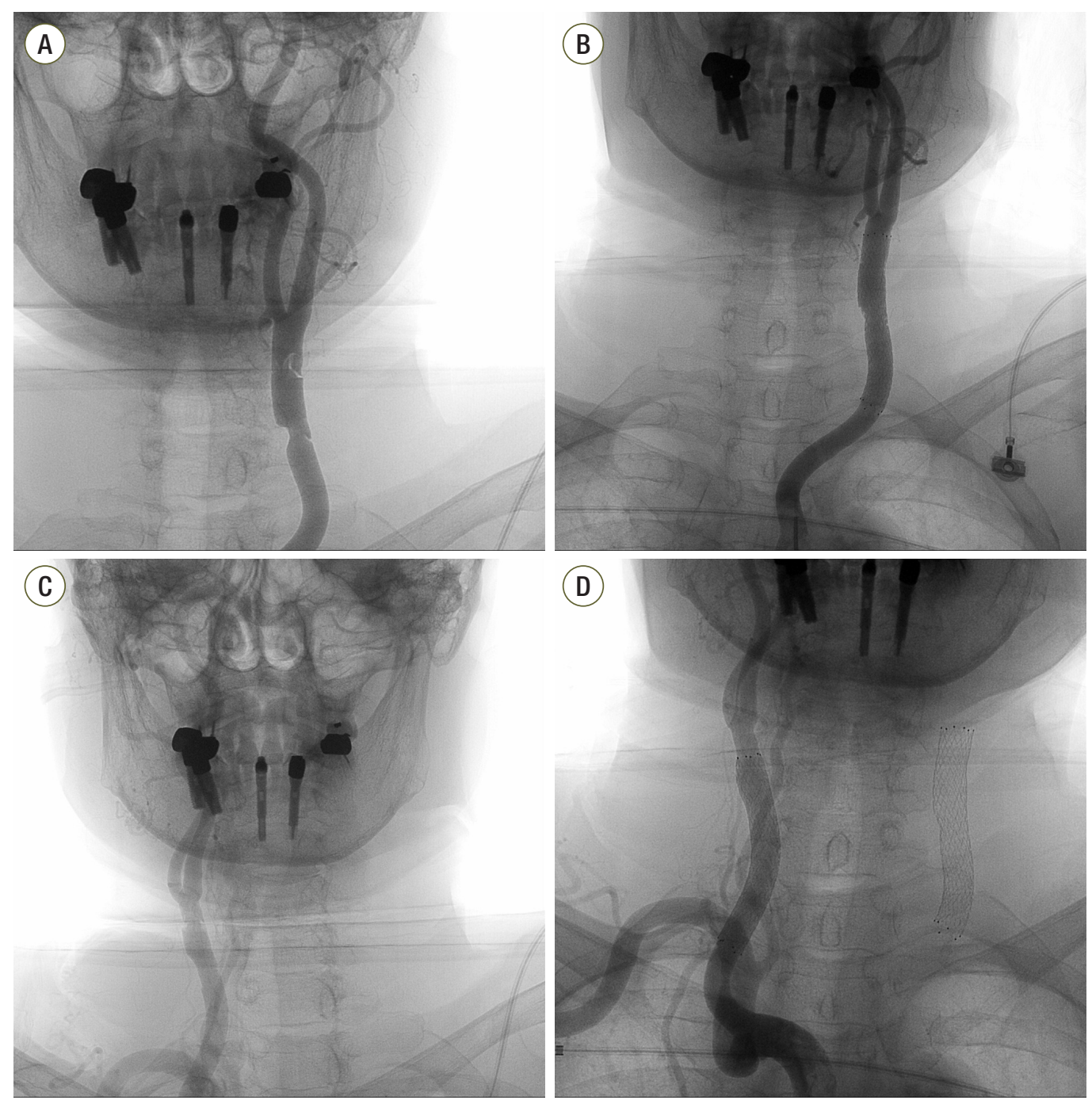

Figure 3. Transfemoral cerebral angiography showing dissection of both distal common carotid arteries. (A) A movable flap was observed according to flow in the left common carotid artery without thrombus. (B) Flow patent after stent insertion in the left common carotid artery. (C) A movable flap was observed according to flow in the right common carotid artery without thrombus. (D) Flow patent after stent insertion in the right common carotid artery.

proved by the institutional review board of Jeju National University Hospital (No. 2016-12-009).

The incidence of carotid artery dissection induced by blunt trauma ranges from less than $1 \%$ to $3 \%$ [2]. The actual incidence can be even higher and remain undiagnosed. Risk factors for traumatic carotid artery dissection include intense physical activity, blunt injury, and penetrating neck trauma.

In general, about $10 \%$ of patients show immediate symptoms. In the first 24 hours after dissection, $55 \%$ had symptoms, and $35 \%$ had no symptoms for more than 24 hours after injury [5]. Patients with immediate symptoms usually have neurological deficits. Headache, including neck and facial pain, pulsatile tinnitus, decreased taste sensation, focal weakness, and migraine-like symptoms.

Carotid artery dissection begins to tear in one of the carotid arteries, and the blood enters the arterial wall and splits the layer. As a result, intramural hematoma or aneurysmal dillatation is created and this process can either be the source of miroemboli. This injury involves an initial intimal tear and exposes the thrombogenic subendothelial collagen, initiating platelet aggregation with 
subsequent thrombus formation that can embolize the artery [6]. Therefore, some studies have recommended an initial antithrombotic regimen $[7,8]$.

In the present case, the patient was unable to undergo antithrombotic therapy at the initial stage due to hematoma-induced neck swelling. On angiography, a thrombus was not present but a visible intimal flap was observed (Figure 3A and C), so the dissection was classified as grade II [9]. The management of low-grade (grade I and II) blunt carotid artery injuries remains controversial. However, antiplatelet agents or anticoagulants are used as first-line treatments, and endovascular stenting is generally reserved for symptomatic or higher-grade blunt injuries [6,10-13]. Low-grade blunt cerebrovascular injuries (BCVI) carry the low risk of cerebral infarction. Griessenauer et al. [14] searched the outcomes in 112 patients with BCVI. They concluded that most ischemic strokes occur before prescreening using CT angiography, and antiplatelet therapy. This indicates that subsequent imaging may not help prevent most ischemic strokes. The progression of injury was not changed by specific treatment or absence of treatment $[13,15]$. However, according to available literature, it is difficult to determine the actual rate of BCVI-related ischemic strokes. The incidence of BCVI-related ischemic stroke has been reported to be as low as $0.05 \%$ and as high as $50 \%[14,16$ 18]. At that time of admission, the risk of active bleeding or cerebral hemorrhage was low, but if the hematoma increased, dyspnea would occur and the patient's management might be difficult. Thus, we did not proceed with the initial antithrombotic therapy and proceeded after the endovascular procedure.

Fortunately, this patient had a temporary neurological symptom that disappeared after stent insertion. There were no new symptoms during the 2 weeks of hospitalization. In addition, the hemorrhage in the neck did not progress after antithrombotic therapy. Therefore, we could manage the patient with low-grade carotid artery dissection with endovascular stent insertion without any complication, despite the delayed initial antithrombotic therapy.

\section{Acknowledgments}

We thank the intensive care unit members and primary care physicians for help and management for this patient.

\section{ORCID}

So Hui Yun

http://orcid.org/0000-0001-9544-5085

Jong Cook Park

http://orcid.org/0000-0002-2728-3181

\section{References}

1. Jansen G, Popp J, Dietrich U, Mertzlufft F, Bach F. Traumatic dissection of the carotid artery: challenges for diagnostics and therapy illustrated by a case example. Anaesthesist 2013;62:817-23.

2. Baker WE, Wassermann J. Unsuspected vascular trauma: blunt arterial injuries. Emerg Med Clin North Am 2004;22:1081-98.

3. Cohen JE, Ben-Hur T, Gomori JM, Umansky F, Lylyk P, Rajz G. Stent-assisted arterial reconstruction of traumatic extracranial carotid dissections. Neurol Res 2005;27 Suppl 1:S73-8.

4. Fateri F, Groebli Y, Rufenacht DA. Intraarterial thrombolysis and stent placement in the acute phase of blunt internal carotid artery trauma with subocclusive dissection and thromboembolic complication: case report and review of the literature. Ann Vasc Surg 2005;19:434-7.

5. Yang ST, Huang YC, Chuang CC, Hsu PW. Traumatic internal carotid artery dissection. J Clin Neurosci 2006;13:123-8.

6. Biffl WL, Ray CE Jr, Moore EE, Franciose RJ, Aly S, Heyrosa MG, et al. Treatment-related outcomes from blunt cerebrovascular injuries: importance of routine follow-up arteriography. Ann Surg 2002;235:699706.

7. Biffl WL, Cothren CC, Moore EE, Kozar R, Cocanour C, Davis JW, et al. Western Trauma Association critical decisions in trauma: screening for and 
treatment of blunt cerebrovascular injuries. J Trauma 2009;67:1150-3.

8. Bromberg WJ, Collier BC, Diebel LN, Dwyer KM, Holevar MR, Jacobs DG, et al. Blunt cerebrovascular injury practice management guidelines: the Eastern Association for the Surgery of Trauma. J Trauma 2010;68:471-7.

9. Biffl WL, Moore EE, Offner PJ, Brega KE, Franciose RJ, Burch JM. Blunt carotid arterial injuries: implications of a new grading scale. J Trauma 1999;47:845-53.

10. Wahl WL, Brandt MM, Thompson BG, Taheri PA, Greenfield LJ. Antiplatelet therapy: an alternative to heparin for blunt carotid injury. J Trauma 2002;52:896-901.

11. Moulakakis KG, Mylonas S, Avgerinos E, Kotsis T, Liapis CD. An update of the role of endovascular repair in blunt carotid artery trauma. Eur J Vasc Endovasc Surg 2010;40:312-9.

12. Cafasso D, Meadows JM, Wolfe SQ, Katras T, Kellicut DC, Golarz SR. Endovascular treatment of bilateral carotid artery pseudoaneurysms after blunt carotid injury. Ann Vasc Surg 2014;28:263.e11-6.

13. Cothren CC, Biffl WL, Moore EE, Kashuk JL, Johnson JL. Treatment for blunt cerebrovascular injuries: equivalence of anticoagulation and antiplatelet agents. Arch Surg 2009;144:685-90.

14. Griessenauer CJ, Fleming JB, Richards BF, Cava LP, Cure JK, Younan DS, et al. Timing and mechanism of ischemic stroke due to extracranial blunt traumatic cerebrovascular injury. J Neurosurg 2013;118:397404.

15. Scott WW, Sharp S, Figueroa SA, Eastman AL, Hatchette CV, Madden CJ, et al. Clinical and radiographic outcomes following traumatic grade 1 and 2 carotid artery injuries: a 10-year retrospective analysis from a level I trauma center. The Parkland Carotid and Vertebral Artery Injury Survey. J Neurosurg 2015;122:1196-201.

16. Eastman AL, Muraliraj V, Sperry JL, Minei JP. CTAbased screening reduces time to diagnosis and stroke rate in blunt cervical vascular injury. J Trauma 2009;67:551-6.

17. Li W, D’Ayala M, Hirshberg A, Briggs W, Wise L, Tortolani A. Comparison of conservative and operative treatment for blunt carotid injuries: analysis of the National Trauma Data Bank. J Vasc Surg 2010;51:593-9.e1-2.

18. Mayberry JC, Brown CV, Mullins RJ, Velmahos GC. Blunt carotid artery injury: the futility of aggressive screening and diagnosis. Arch Surg 2004;139:609-12. 